\title{
Distribution and reproductive ecology of the Antarctic octocoral Ainigmaptilon antarcticum in the Weddell Sea
}

\author{
C. Orejas ${ }^{1, *}$, P. J. López-González ${ }^{2}$, J. M. Gili ${ }^{3}$, N. Teixidó ${ }^{1}$, J. Gutt ${ }^{1}$, W. E. Arntz ${ }^{1}$ \\ ${ }^{1}$ Alfred-Wegener-Institut für Polar- und Meeresforschung, Columbusstraße, 27568 Bremerhaven, Germany \\ ${ }^{2}$ Departamento de Fisología y Zoología, Facultad de Biología, Universidad de Sevilla, \\ Reina Mercedes, 6, 41012 Sevilla, Spain \\ ${ }^{3}$ Institut de Ciències del Mar, CMIMA-CSIC, Passeig Maritim de la Barceloneta 37-49, 08003 Barcelona, Spain
}

\begin{abstract}
The spatial distribution, density and reproductive ecology of Ainigmaptilon antarcticum was studied using samples (colonies) collected during the EASIZ (Ecology of the Antarctic Sea Ice Zone) cruises I, II, and III, (1996, 1998, and 2000). Samples were taken using Agassiz and bottom trawls between 150 and $600 \mathrm{~m}$ depth in conjunction with a Remotely Operated Vehicle (ROV, video recording transects). A. antarcticum showed a very patchy distribution with a mean density of 12 per $100 \mathrm{~m}^{2}(\mathrm{SD} \pm 23)$ in the study area. This gorgonian species is gonochoric with a sex ratio of 1:1. Two size classes of oocytes in different developmental stages were observed in summer (January to March) and autumn (April to May), ranging from 25 to $700 \mu \mathrm{m}$ in summer, and from 20 to $900 \mu \mathrm{m}$ in autumn. Differences in developmental stages among different zones of the colony were observed. The apical and medial part showed the highest fecundity. The distribution of gonad size differed between summer and autumn. The relative frequency of the largest oocyte size class decreased in the autumn samples. No larvae were found. The results are discussed in the context of the relationship between reproductive strategies of marine invertebrates and environmental factors.
\end{abstract}

KEY WORDS: Antarctic octocorals $\cdot$ Reproductive patterns $\cdot$ Distribution

\section{INTRODUCTION}

Antarctic shelf communities are dominated by sessile invertebrates (Dayton et al. 1974, White 1984, Voß 1988). Anthozoans (mainly gorgonians) are the second most dominant macrobenthic taxon in abundance in the Weddell Sea (Starmans et al. 1999). Moreover, anthozoans, and especially gorgonians, are also common organisms in sublittoral benthic communities in temperate (e.g. Weinberg 1979, 1980, Gili et al. 1989) and tropical areas (e.g. Kinzie 1973, Grigg 1977, Muzik 1982, Lasker et al. 1983, Yoshioka \& Yoshioka 1989). Despite the importance of gorgonians in polar regions, there have been very few studies on their basic ecology (Arntz et al. 1994).

*E-mail: orejas@zmt.uni-bremen.de
As one of the main contributors to the structure of Antarctic benthic communities gorgonians, like other sessile organisms, interact with physical factors as 'ecosystem engineers' (Jones et al. 1997), modifying the environment and the structure of the community. Their spatial distribution pattern, which in the case of sessile marine organisms is closely related with reproductive strategy and reproductive success (Levinton 1982), reflects this level of interference with the environment. Knowledge about abundance and reproduction of the dominant species in suspension feeder communities is a prerequisite for understanding the role of the benthic compartment in polar ecosystems and a necessary complementation of the-usually more extensive - studies on motile species (Dayton 1990).

The distributional patterns of many invertebrate benthic megafauna species have been shown to be patchy (e.g. Picken 1980, Miller 1998). Contagious pat- 
terns of distribution have been found for anthozoans (Williams 1976), and several octocoral species also show a patchy and clumped distribution, which may favour reproduction (e.g. Chia \& Crawford 1973, Langton et al. 1990, Rice et al. 1992). However, most of these studies have been undertaken in tropical and temperate regions (but see Gili et al. 1999).

Similarly, patterns of reproduction of anthozoans have been well studied in temperate and tropical regions (e.g. Weinberg \& Weinberg 1979, Hughes \& Jackson 1980, Martin 1982, Brazeau \& Lasker 1990, Coma et al. 1995a). Gonochorism and a sex ratio of 1:1 are considered the general pattern for this group in the Caribbean Sea (Kinzie 1970, 1974, Goldberg \& Hamilton 1974, Behety-González \& Guardiola 1979, Martin 1982), the Pacific Ocean (Grigg 1977) and the Mediterranean Sea (Coma et al. 1995a). Other important reproductive features are seasonality in gamete production and individual size at first reproduction (Sebens 1982, Hughes \& Cancino 1985). Some work has been done on reproductive patterns of deep-sea cnidarians, mainly actinians (e.g. Van Praet 1990, Van Praet et al. 1990), zoantharians (Muirhead et al. 1986), and sea pens (e.g. Rice et al. 1992, Tyler et al. 1995, Eckelbarger et al. 1998), however, information on polar species is scarce (e.g. Arntz et al. 1992, Barthel \& Gutt 1992, Poulin \& Féral 1996, Brito et al. 1997, Barnes \& Clarke 1998). To our knowledge the study of the gorgonian Thouarella variabilis (Brito et al. 1997) provides the only data on reproductive ecology available for Antarctic gorgonians so far, although descriptive information on reproductive modes of some Antarctic octocorals was first obtained a long time ago (in Brito et al. 1997: e.g. Wright \& Studer 1889, Versluys 1906). These papers suggest gonochorism and brooding to be common features of Antarctic and deep-sea octocorals.

To overcome the obvious lack of basic ecological data on many benthic species in the Antarctic, the international research programme EASIZ (Ecology of the Antarctic Sea Ice Zone) of SCAR (Scientific Committee for Antarctic Research) was designed to concentrate on the ecology of more abundant ('key') species. These basic data are a prerequisite for determining the role of benthic biota in polar regions.

Our approach concentrated on dominant species within the sessile suspension feeder fraction. It is the first to deal explicitly with that group, which is always mentioned as the most conspicuous group of organisms in the Antarctic benthos, whereas the bulk of studies continues to deal with motile species such as crustaceans, fishes, or echinoderms (Arntz et al. 1994).

Consequently, the present study, as part of the EASIZ, was conducted on a common gorgonian that makes an outstanding contribution to the structure of Antarctic epibenthic communities. The principal aim of this study is to investigate the reproductive ecology of a gorgonian species under the specific Antarctic conditions (i.e. strong seasonality, also in terms of food availability, and very cold water), and to compare it with that of similar species in lower latitudes. We also investigate the role of distributional patterns for reproductive success. This involves the following steps: (1) to determine patterns of density and spatial distribution of the Antarctic gorgonian Ainigmaptilon antarcticum; and (2) to study the reproduction of this species (distribution of gonads within a colony, number of oocytes produced, seasonality in gonad production and spawning). We discuss the relationship between distribution and reproductive output, and compare our results with the patterns described for species of octocorals from other latitudes, as well as with other Antarctic benthic organisms.

\section{MATERIALS AND METHODS}

This study was carried out in the eastern Weddell Sea (Antarctica; Fig. 1). Sampling was carried out on board of the German RV 'Polarstern' (for details on the expeditions see Arntz \& Gutt 1997, 1999, Arntz \& Brey 2001), during the EASIZ cruises I (ANT XIII/3, January to March 1996), II (ANT XV/3, January to March 1998) and III (ANT XVII/3; March to May 2000). The sampled area was characterised by Voß (1988), who described the presence of sandy bottoms but also sponge spicule mats, bryozoan debris and a few stones. A high number of taxa, species diversity and evenness are also characteristics of the Kapp Norvegia area.

Spatial patterns of density. Transects were conducted with a Remotely Operated Vehicle (ROV; for a detailed description see Starmans et al. 1999) and recorded using a video camera, at depths ranging between 142 and $363 \mathrm{~m}$. Five transects from EASIZ I and 12 from EASIZ II, each covering areas between 378 and $1696 \mathrm{~m}^{2}$ and corresponding to a total of $13921 \mathrm{~m}^{2}$, were studied (Table 1). Each transect was split into adjacent areas (sampling units) of approximately $100 \mathrm{~m}^{2}$ and 4 of those sampling units of each transect were randomly selected to obtain density values, in order to avoid statistically dependent samples. The degree of contagiousness of the population was determined using the variance to mean ratio $\left(S^{2}: \bar{x}\right)$ and Morisita's index of dispersion ( $I_{\mathrm{d}}$ Morisita 1962). Random spatial distribution is indicated when the value of this index equals 1 , while the distribution tends to be contagious as the value becomes greater than 1 . Randomness of the null hypothesis was tested by a $\chi^{2}$-test at $5 \%$ significance level.

Reproduction. Samples were collected with Agassiz, bottom, and benthopelagic trawls, and with a small 


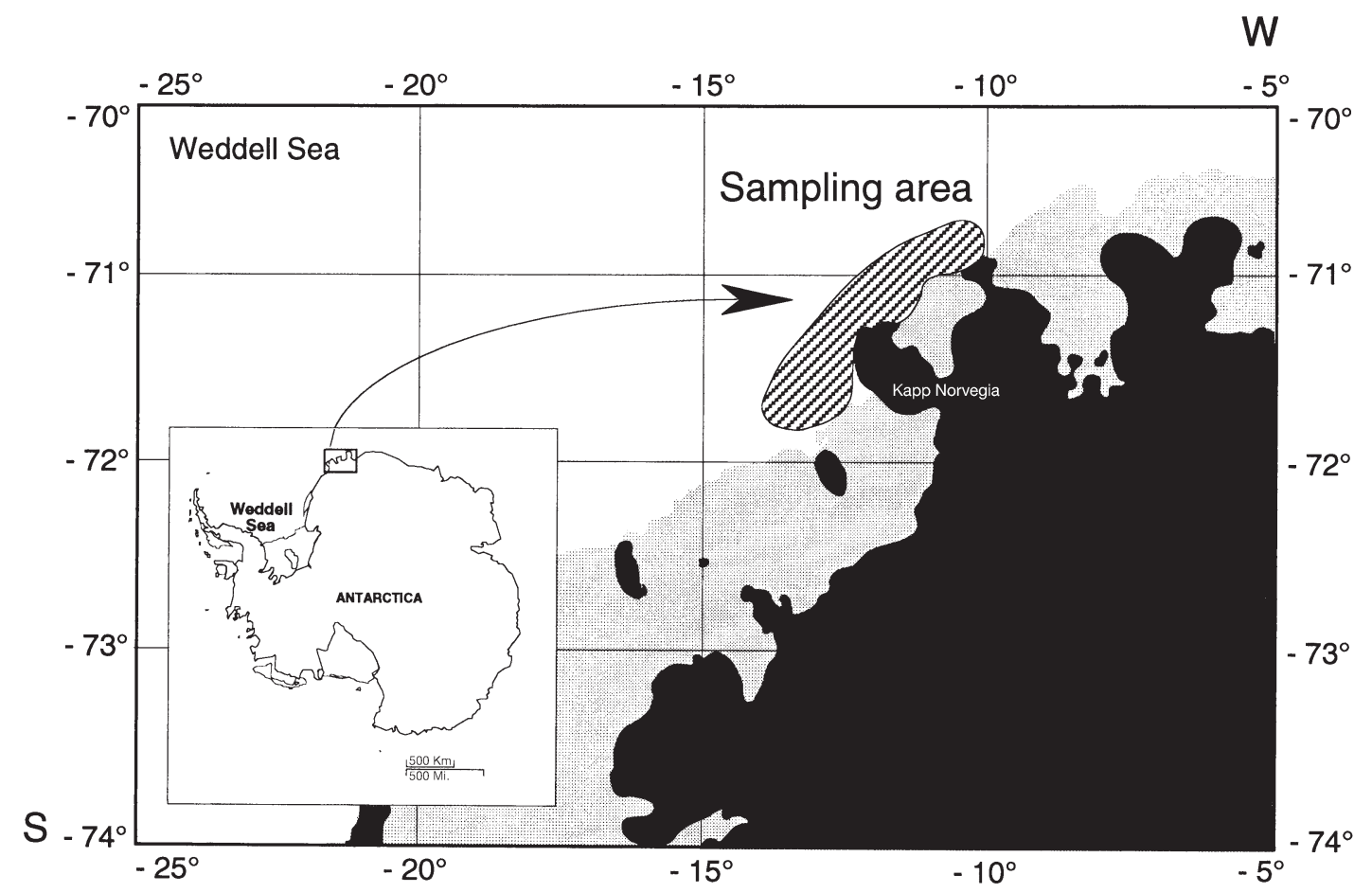

Fig. 1. Map of the sampling area in the eastern Weddell Sea (Antarctica)

Table 1. Ainigmaptilon antarcticum. Density values in the Weddell Sea and values of $\mathrm{S}^{2}: \overline{\mathrm{X}}$ and Morisita's Index $\left(I_{\mathrm{d}}\right) . \mathrm{SW} / \mathrm{KN}$ : Southwest of Kapp Norvegia; NW/KN: northwest of Kapp Norvegia; W/KN: west of Kapp Norvegia; NE/KN: northeast of Kapp Norvegia; N/KN: north of Kapp Norvegia; KN: Kapp Norvegia; AB: Atka Bay. An asterisk indicates a significant deviation from random for both $\mathrm{S}^{2}: \overline{\mathrm{x}}$ and $I_{\mathrm{d}}$ at the $5 \%$ level $\left(\chi^{2}\right.$-test)

\begin{tabular}{|c|c|c|c|c|c|c|c|c|c|}
\hline \multirow[t]{2}{*}{ Cruise } & \multirow[t]{2}{*}{ Area } & \multirow[t]{2}{*}{ Transect } & \multicolumn{2}{|c|}{ Position } & \multirow{2}{*}{$\begin{array}{l}\text { Depth } \\
\text { (m) }\end{array}$} & \multirow{2}{*}{$\begin{array}{c}\text { Total area } \\
\text { sampled }\left(\mathrm{m}^{2}\right)\end{array}$} & \multirow{2}{*}{$\begin{array}{c}\bar{x} \pm \mathrm{SD} \\
\text { ind } / 100 \mathrm{~m}^{2}\end{array}$} & \multirow[t]{2}{*}{$\mathrm{S}^{2}: \bar{x}$} & \multirow[t]{2}{*}{$I_{\mathrm{d}}$} \\
\hline & & & Lat (S) & Long (W) & & & & & \\
\hline EASIZ I & $\mathrm{SW} / \mathrm{KN}$ & 1 & $71^{\circ} 40.54^{\prime}$ & $12^{\circ} 44.48^{\prime}$ & 226 & 705 & $37.3 \pm 54.5$ & $79.77^{*}$ & $2.60^{*}$ \\
\hline EASIZ I & NW/KN & 2 & $71^{\circ} 18.13^{\prime}$ & $12^{\circ} 15.99^{\prime}$ & 175 & 1203 & $1.5 \pm 2.4$ & 3.78 & $2.67^{*}$ \\
\hline EASIZ I & $\mathrm{W} / \mathrm{KN}$ & 3 & $71^{\circ} 33.09^{\prime}$ & $12^{\circ} 20.58^{\prime}$ & 363 & 654 & $3.5 \pm 2.4$ & 1.62 & 1.14 \\
\hline EASIZ I & $\mathrm{NE} / \mathrm{KN}$ & 4 & $71^{\circ} 07.33^{\prime}$ & $11^{\circ} 26.79^{\prime}$ & 142 & 1341 & 0 & - & - \\
\hline EASIZ I & NW/KN & 5 & $71^{\circ} 20.50^{\prime}$ & $12^{\circ} 23.90^{\prime}$ & 198 & 1115 & 0 & - & - \\
\hline EASIZ II & $\mathrm{N} / \mathrm{KN}$ & 1 & $70^{\circ} 52.04^{\prime}$ & $10^{\circ} 32.40^{\prime}$ & 229 & 503 & $3.3 \pm 4.7$ & 6.85 & $2.46^{*}$ \\
\hline EASIZ II & N/KN & 2 & $70^{\circ} 53.82^{\prime}$ & $10^{\circ} 33.85^{\prime}$ & 244 & 378 & $1.0 \pm 1.4$ & 2.00 & 2.00 \\
\hline EASIZ II & N/KN & 3 & $70^{\circ} 52.15^{\prime}$ & $10^{\circ} 29.34^{\prime}$ & 233 & 1325 & $0.5 \pm 0.6$ & 0.67 & 0.00 \\
\hline EASIZ II & $\mathrm{N} / \mathrm{KN}$ & 4 & $70^{\circ} 53.28^{\prime}$ & $10^{\circ} 27.80^{\prime}$ & 242 & 495 & 0 & - & - \\
\hline EASIZ II & $\mathrm{N} / \mathrm{KN}$ & 5 & $70^{\circ} 51.93^{\prime}$ & $10^{\circ} 32.32^{\prime}$ & 231 & 774 & $1.3 \pm 1.5$ & 1.80 & 1.60 \\
\hline EASIZ II & N/KN & 6 & $70^{\circ} 50.77^{\prime}$ & $10^{\circ} 30.50^{\prime}$ & 235 & 567 & $0.8 \pm 1.5$ & 3.00 & $4.00^{*}$ \\
\hline EASIZ II & N/KN & 7 & $70^{\circ} 49.32^{\prime}$ & $10^{\circ} 28.92^{\prime}$ & 281 & 1696 & $32.8 \pm 24.7$ & $18.61^{*}$ & $1.41^{*}$ \\
\hline EASIZ II & $\mathrm{KN}$ & 8 & $71^{\circ} 13.56^{\prime}$ & $12^{\circ} 25.48^{\prime}$ & 253 & 841 & $19.3 \pm 22.9$ & $27.13^{*}$ & $2.03^{*}$ \\
\hline EASIZ II & $\mathrm{KN}$ & 9 & $70^{\circ} 50.56^{\prime}$ & $10^{\circ} 34.97^{\prime}$ & 261 & 590 & $55.3 \pm 41.0$ & $30.48^{*}$ & $1.40^{*}$ \\
\hline EASIZ II & $\mathrm{AB}$ & 10 & $70^{\circ} 47.37^{\prime}$ & $10^{\circ} 24.83^{\prime}$ & 297 & 568 & $37.3 \pm 30.4$ & $24.78^{*}$ & $1.48^{*}$ \\
\hline EASIZ II & $\mathrm{AB}$ & 11 & $70^{\circ} 51.71^{\prime}$ & $10^{\circ} 45.24^{\prime}$ & 312 & 652 & $1.5 \pm 1.3$ & 1.10 & 1.07 \\
\hline EASIZ II & $\mathrm{KN}$ & 12 & $71^{\circ} 13.79^{\prime}$ & $12^{\circ} 14.93^{\prime}$ & 275 & 517 & $5.3 \pm 6.4$ & 7.79 & $2.02^{*}$ \\
\hline
\end{tabular}

dredge at depths ranging between 250 and $600 \mathrm{~m}$. All specimens were preserved in $4 \%$ formalin prior to further work in the laboratory. A total of 136 colonies (indicated by the presence of the holdfast) were examined for sex ratio. A $\chi^{2}$-test was done in order to test for statistically significant differences in the frequency of individuals of both sexes.
Studies on the anatomy of the genus Ainigmaptilon (Dean 1926, Molander 1929, Carlgren 1943, Bayer 1954) showed that the polyps tend to fuse at different levels, forming distinct polyp leaves (Fig. 2). The selected 'working unit' for all the reproductive studies was the polyp leaf because of the difficulty of isolating the gonadal products from each gastrovascular cavity 


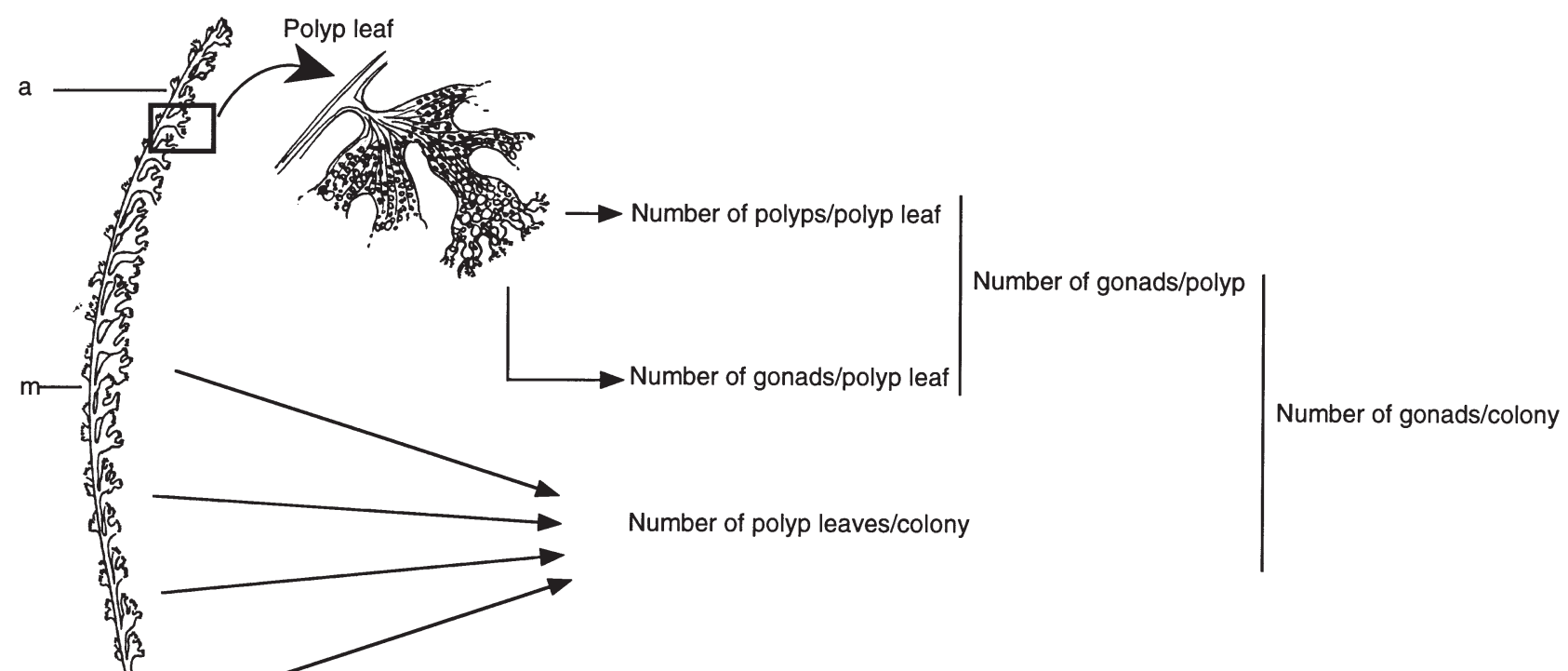

Fig. 2. Ainigmaptilon antarcticum. Morphology of a colony. Apical (a), medial (m) and b basal (b) zones are indicated, as well as the methodology employed to calculate the fecundity of a colony

during dissection (Dean 1926). The selection of the polyp leaf as the working unit was based on preliminary morphological and histological studies which confirmed the discontinuity of the gastrovascular cavities in A. antarcticum. Selected polyp leaves previously fixed in formalin were washed in distilled water, dehydrated in acetone, and subsequently dried with $\mathrm{CO}_{2}$ in a Balzer CPD 030 Critical Point Dryer for scanning electron microscopy (SEM) morphological studies. Samples were mounted on stubs by a carbon-impregnated film, coated with $20 \mathrm{~nm}$ gold in an Edwards \& Kniese Vakuum Coating System E 306 A, and observed with a Philipps scanning electron microscope SEM 515 at an acceleration voltage of $10.2 \mathrm{kv}$. For the histological observations we selected portions of fixed colonies, dehydrated them in butanol (Johansen 1940), and embedded them in paraffin wax. Histological sections that were 6 to $10 \mu \mathrm{m}$ thick were mounted and stained with Ramón y Cajal's Triple Stain (Gabe 1968). The sections were also used to confirm and identify the developmental stages of the gonads.

The rest of the reproductive studies were done using a binocular microscope. After dissection gonads were measured using an eyepiece calibrated against a stage micrometer. The number of polyps per polyp leaf and the number of polyp leaves per colony were counted in 6 colonies collected during EASIZ I ( 3 females and 3 males). The lengths of 60 polyps per leaf were measured. To determine fecundity (according to the definition given by Lincoln et al. 1998), the number of gonads per polyp in 5 colonies from EASIZ I ( 3 females and 2 males) and 5 colonies from EASIZ II ( 2 males and 3 females) were examined. Total numbers of oocytes and spermatic cysts per polyp leaf were counted in 3 zones (apical, medial and basal) of the colony (Fig. 2). Two leaves per zone were analysed for each zone of each colony. Oocyte and spermatic cyst counts were done in the summer samples only, in order to avoid the possible error of overlooking gametes released during the autumn season.

To determine developmental stages, 11 colonies from EASIZ I ( 8 females and 3 males), 10 colonies from EASIZ II ( 5 females and 5 males), and 20 colonies from EASIZ III (10 females and 10 males) were selected. The relatively low number of specimens available for examination was caused by the fragility and the consequent difficulty of obtaining complete colonies. The developmental stage of the gonads was studied in each colony in the apical, medial and basal zones (Fig. 2), following the methodology described by Brazeau \& Lasker (1990), Coma et al. (1995b), and Brito et al. (1997). In all the colonies (41), 200 gonads per colony zone were randomly selected and measured.

Our data set for number and size of gonads was not distributed normally, despite different transformations. Since a 3-way ANOVA was necessary to test both individual effects and interactions of the factors cruise, sex and colony zone on gonad size and number, parametric tests were used. To achieve a distribution as near as possible to a normal distribution and to meet the homocedasticity assumption, data were subjected to BoxCox transformations (Sokal \& Rohlf 1995). In cases of significant differences, a Bonferroni/Dunn post hoc analysis of means was performed. For data transformation and further statistical analyses, we used the statistical package Statview (SAS Institute 1998). 

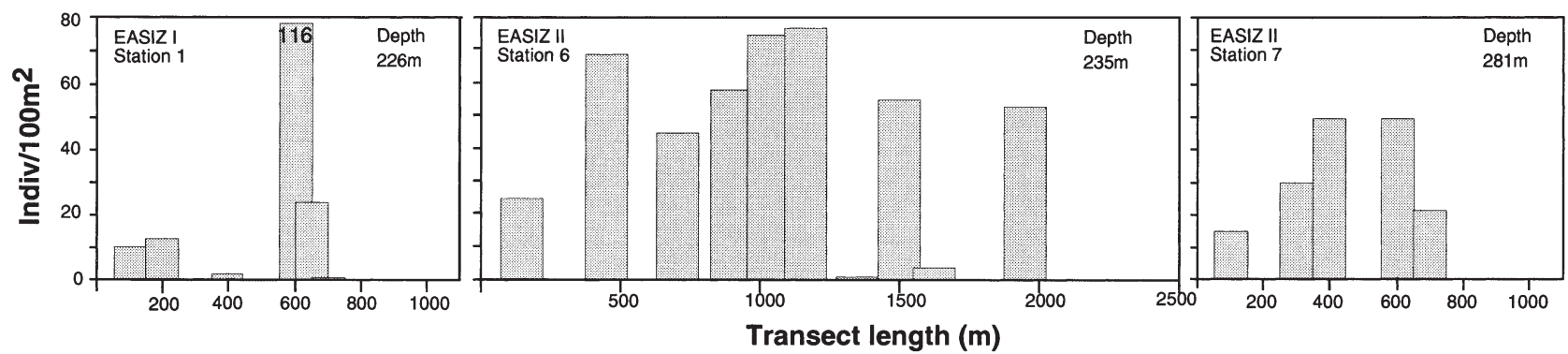

Fig. 3. Ainigmaptilon antarcticum. Density in 3 different transects in the area of Kapp Norvegia (Weddell Sea)

\section{RESULTS}

\section{Density and distribution}

The mean density for all transects was 12 ind. per $100 \mathrm{~m}^{2}(\mathrm{SD} \pm 23)$ (Table 1$)$. The high variance (much higher than the mean value) indicated a very patchy distribution for Ainigmaptilon antarcticum. The average patch size was $34 \mathrm{~m}^{2}(\mathrm{SD} \pm 30$; patch area ranged from 3 to $98 \mathrm{~m}^{2}$ ), and the average density of individuals (excluding zeros) was 17 ind. per $100 \mathrm{~m}^{2}$ (SD \pm 31 ).

In all transects except 1 (Transect 3, EASIZ II), values of Morisita's index of dispersion exceeded unity (Table 1; in 3 other transects density was zero), suggesting that Ainigmaptilon antarcticum has a contagious distribution. Analysis of $\chi^{2}$ statistic showed that the values of Morisita's index differed significantly from a random distribution for most of the analysed transects $(p<0.05$, Table 1). This indicates that $A$. antarcticum is patchily distributed also at scales smaller (dozens of meters) than the area covered by the transects (Fig. 3). Comparative densities of $A$. antarcticum on 3 transects revealed a discontinuity in the density values which varied between 0 and 116 ind. per $100 \mathrm{~m}^{2}$. For example, in Stn 1 of EASIZ I (see Fig. 3 left), the lowest abundance in units that showed presence of $A$. antarcticum was 5 ind. per $100 \mathrm{~m}^{2}$, whereas in the next $200 \mathrm{~m} 116$ ind. per $100 \mathrm{~m}^{2}$ were recorded.

\section{Reproductive features}

All colonies examined were found to be reproductive. Ainigmaptilon antarcticum is a gonochoric species, and the sex ratio is approximately $1: 1\left(\chi^{2} ; \mathrm{p}>\right.$ 0.05). The polyp leaves of $A$. antarcticum are dichotomously ramified (Fig. 2). Internally, gastrovascular cavities are longitudinally arranged and separated by thin mesogloea walls covered by the gastrodermic epithelium, although the cavities of contiguous polyps are not always completely separated (Fig. 2). The gonads fill all the available space in the canals (Figs. 2
$\& 4 \mathrm{a}, \mathrm{b})$, and have the general structure shown by other octocorals (Fig. 4c,d).

Oogenesis is similar to that described for other anthozoans. Alterations in the nucleus do not take place until the oocyte reaches the final size, when the distinct nucleolus and line between germ vesicle and cytoplasm, observed during the early oogenesis, disappear during the maturation of the large oocytes. Mature oocytes are finally detached from the mesenteries. No embryonic or planula stages have been observed in the gastrovascular cavities of the polyp leaves.

The average number of oocytes per single gastrovascular cavity (polyp) was 3 (SD \pm 2 ), and the average number of spermatic cysts was $1(\mathrm{SD} \pm 1)$. Results of the 3-way ANOVA for number of gonads are shown in Table 2. Significant interactions precluded us from testing for the main effects but the Bonferroni/Dunn post hoc test revealed that there were no significant differences in the average number of gonads per polyp between cruises (Table 2, Fig. 5a). Differences in the mean number of gonads were found between the medial-basal and the apical-basal zones in males but not in females. Significant differences were also detected between medial-basal and apical-basal zones in EASIZ I, and between the medial-basal zones in EASIZ II. Numbers of gonads between females and males were significantly different in EASIZ II. Differences in numbers of gonads between females and males have been detected for both cruises in the basal zone.

Results of the 3-way ANOVA for gonad size are shown in Table 3. Again, significant interactions precluded us from testing for the main effects. The Bonferroni/Dunn post hoc test revealed significant differences in gonad size among the 3 cruises (Table 3, Fig. 5b). In all cases, the larger gonads of both males and females were located in the apical and medial. Significant differences in gonad size have been detected for both sexes in the 3 zones (Table 3). Significant differences were also detected among the 3 zones in EASIZ I and EASIZ II and between medial- 

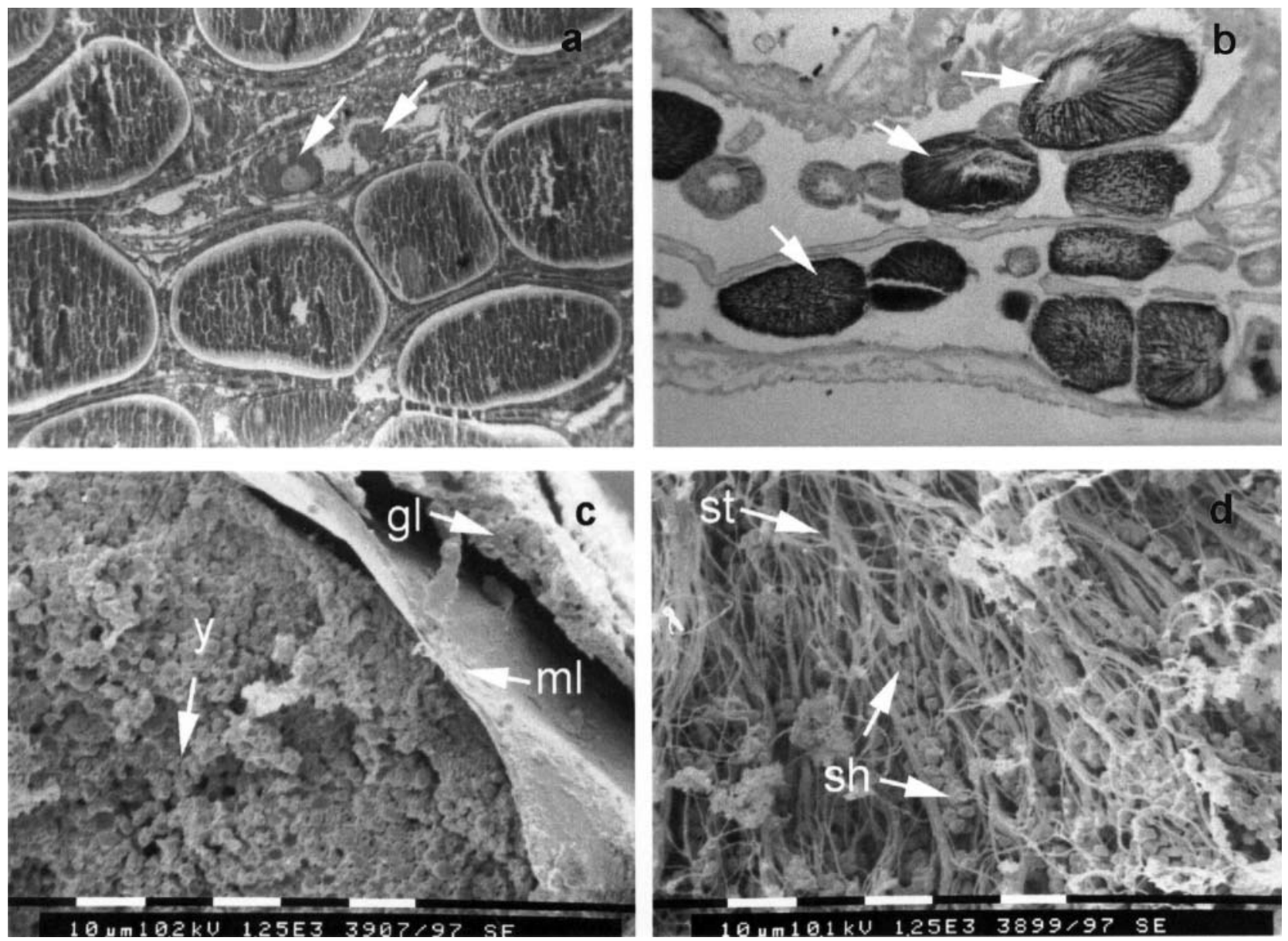

Fig. 4. Ainigmaptilon antarcticum. Gonadal histology and anatomy. (a) Female colony showing the 2 different generations of oocytes ( 2 early oocytes are shown by arrows). Note the remarkable difference in size with surrounding mature oocytes. (b) Male colony showing the spermatic cysts (3 are shown by arrows). Note the characteristic radial arrangement of the sperm. (c) SEM image of a sectioned mature oocyte. Note the yolk granules (y), the mesogleal layer ( $\mathrm{ml}$ ) and the gastrodermal layer ( $\mathrm{gl}$ ). (d) SEM image of a sectioned spermatic cyst. Note the radial arrangement of the sperm, the sperm heads (sh) at the outer zones of the cyst, and the sperm tails (st) oriented to the central zones of the cyst

basal and apical-basal in EASIZ III. The analysis also showed significant differences in the size of gonads between females and males in all cruises and also among the different levels of the colony (Table 3).

Frequency distributions of the oocytes in females, and of sperm cysts in males, from summer and autumn samples are shown in Fig. 6. Two modes in gamete size were clearly distinguishable in females, however this tendency was not observed in males. Summer samples (January to March) showed a first class of oocytes of about 25 to $400 \mu \mathrm{m}$ in diameter in females, and a second size class, mainly oocytes in the last stages and early embryos of about 400 to $700 \mu \mathrm{m}$. The largest size class of oocytes was more abundant in the apical and medial zones of the colonies, whereas those between 25 and $400 \mu \mathrm{m}$ predominantly occurred in the basal part (Fig. 6). In both cases the first mode was larger than the second one. The autumn samples (April to May) for females presented almost only 1 distinct mode, which corresponded to the first summer mode (size). The first size class ranging between 25 and $400 \mu \mathrm{m}$ in the summer samples showed a displacement to a larger diameter in both sexes in autumn.

In males it was possible to distinguish only 1 mode both in summer and autumn. In summer, the size of spermatic cysts ranged between $<50$ and $1000 \mu \mathrm{m}$, while in autumn the size range was not so widespread (Fig. 6). The size of the spermatic cysts also varied between seasons for the different zones of the colony. In the autumn samples the sizes of the spermatic cysts were homogeneous among zones of the colony, while in summer smaller spermatic cysts were more abundant in the basal zone. 
Table 2. Ainigmaptilon antarcticum. Three-way ANOVA comparing numbers of gonads. (Box-Cox transformed) between (a) cruises, (b) colony zone, and (c) sexes

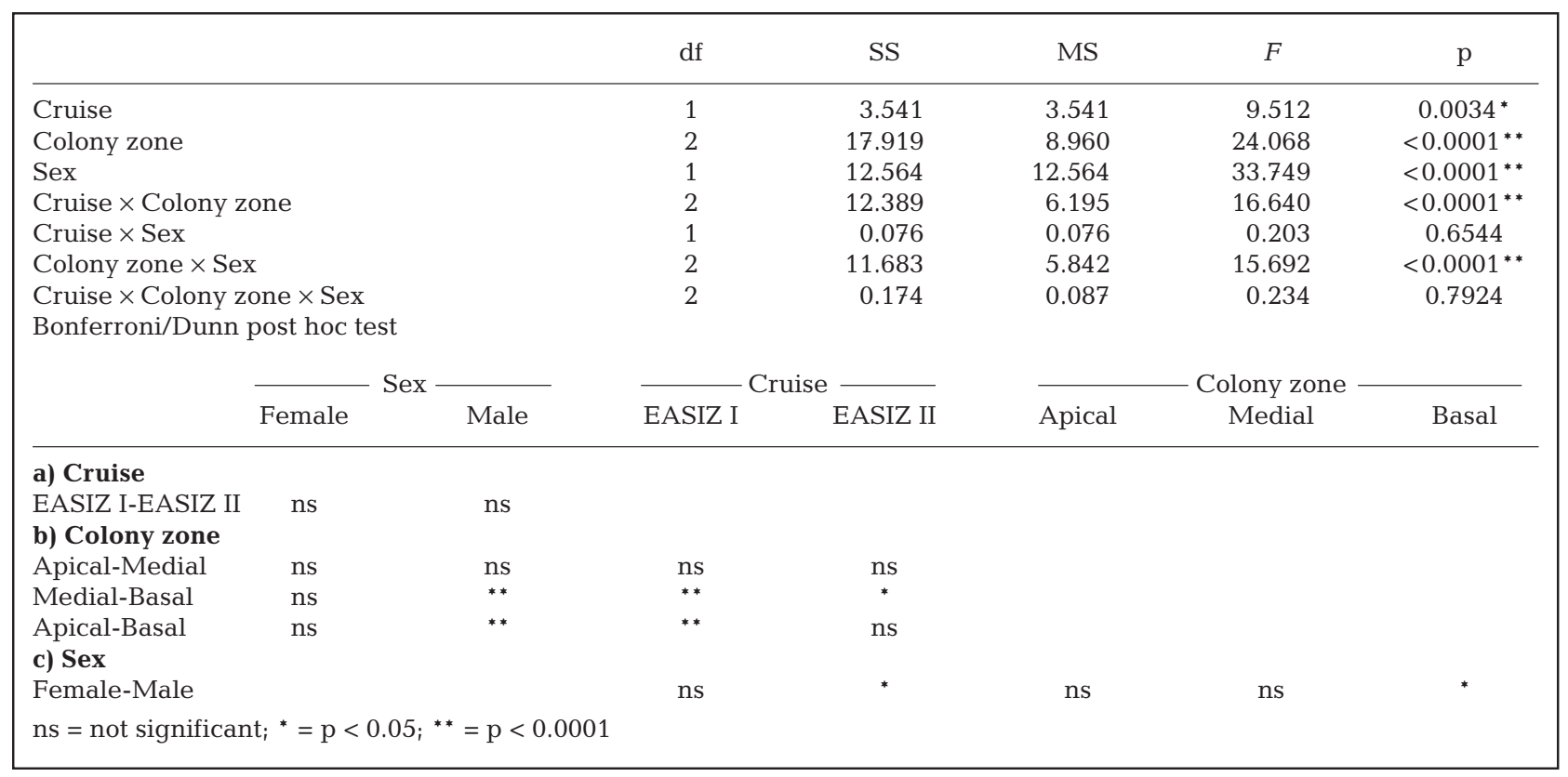

\section{DISCUSSION}

\section{Distribution and reproductive patterns}

The density and spatial distributional patterns observed for Ainigmaptilon antarcticum in the Weddell Sea are similar to those observed in other Antarctic gorgonians (Gili et al. 1999). The low mean densities contrast with the high densities observed for some shallow water and continental shelf gorgonians in temperate and tropical regions (e.g. Kinzie 1973, Grigg 1977, Gili \& Ros 1985).

Density and fecundity at the polyp level seem to be inversely correlated in benthic cnidarians. For example Umbellula lindahli exhibits very low densities but high fecundity at the polyp level (Tyler et al. 1995). Conversely, the pennatulacean Ptilosarcus guerney presents high densities and fecundity is very low at the polyp level (but high at the colony level; Chia \& Crawford 1973). Ainigmaptilon antarcticum seems to follow the latter pattern.

The distance between females and males is a critical factor in the reproduction in benthic sessile invertebrates (Coma \& Lasker 1997). Pennington (1985) showed that echinoid sperm shed into seawater is sufficiently diluted, by turbulent mixing, to prevent fertilization of eggs more than a few metres away from the male. This may not be a major problem in mobile forms such as the echinoids, which can aggregate to ensure successful fertilisation (Young et al. 1992). A similar behaviour has also been observed in the Antarctic limpet Nacella concinna, which forms short-term spawning aggregations (Picken 1980). However, in sessile organisms occurring at low densities, distance between females and males must be of paramount importance in determining reproductive success. The aggregated (contagious) distribution observed in many sessile benthic invertebrates is thus critical to their successful reproduction (Rice et al. 1992). Aggregated distributions have been reported for cnidarian species of continental shelves in other latitudes (e.g. Kophobelemnon stelliferum, Rice et al. 1992, Hecker 1994), and were also found in Ainigmaptilon antarcticum. Both aggregation and increased fecundity may favour reproduction success; however, the lack of data on the dispersal mode of this species prevents us from confirming this hypothesis for A. antarcticum. Other factors, such as synchrony of spawning, may positively affect fertilization of this free-spawning species (e.g. Langton et al. 1987).

\section{Fecundity}

Ainigmaptilon antarcticum exhibits a reproductive strategy characterised by a relatively low number of oocytes per polyp but a high number of polyps in the colony. The different values of gonad number/polyp observed in both sexes arise because not all the polyps contribute the same reproductive effort to the total 
a
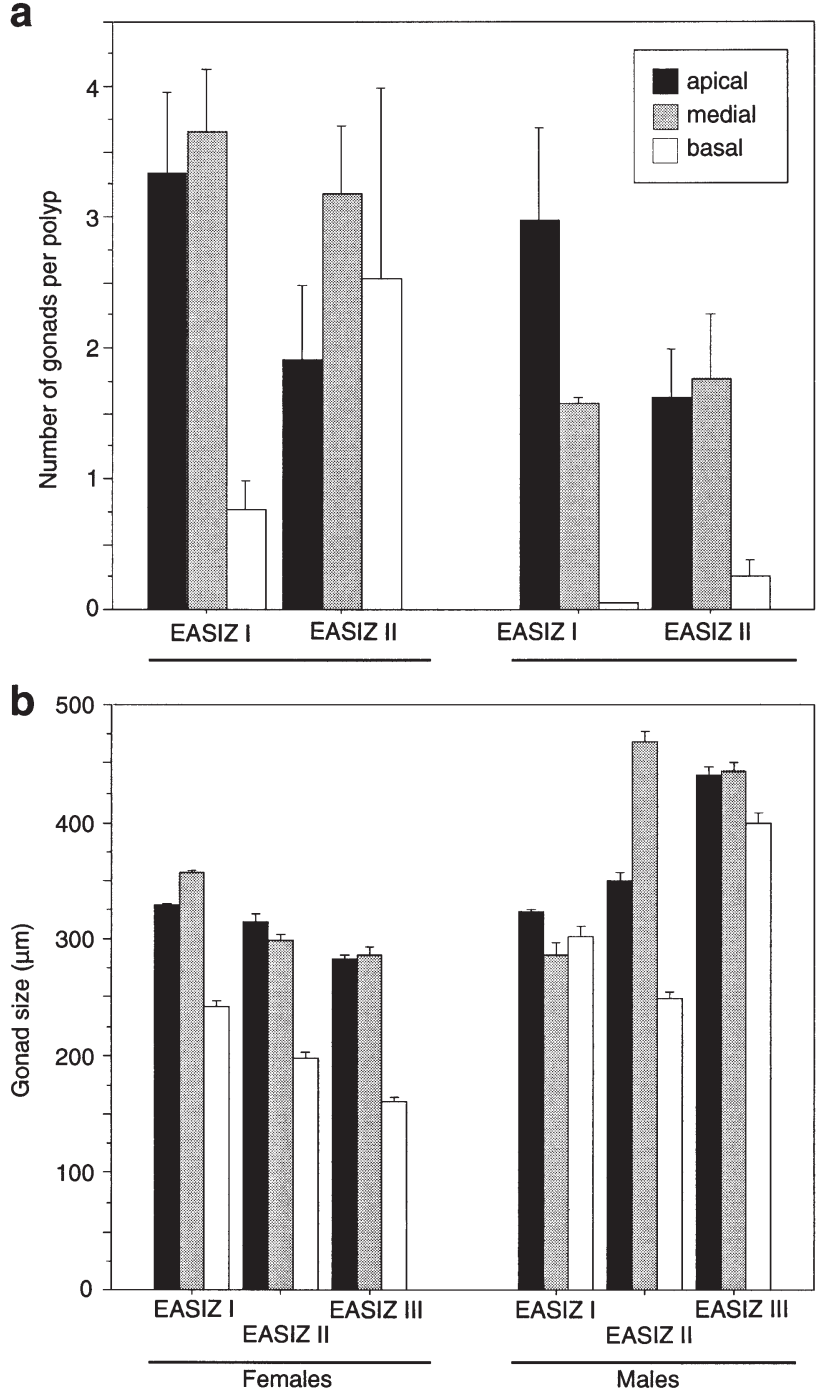

Fig. 5. (a) Ainigmaptilon antarcticum. Mean number of gonads along the colony (apical, medial and basal zones) per polyp in both sexes for the EASIZ I and EASIZ II cruises. (b) Mean size of the gonads along the colony (apical, medial and basal zones) per polyp in both sexes for the EASIZ I, EASIZ II and EASIZ III cruises. Bars indicate standard error

fecundity of the polyp leaf. This contribution probably depends on the age of the polyps, which correlates with the length of their respective gastrovascular cavities.

Fecundity in gorgonians is frequently correlated with colony size (e.g. Kinzie 1974, Grigg 1977, Wahle 1983, Benayahu \& Loya 1984, Coma et al. 1995b). In contrast, we did not find a relationship between colony size of Ainigmaptilon antarcticum and reproductive effort, but this may be a result of the low number of complete colonies available for examination. A large adult $A$. antarcticum is capable of producing 17000 oocytes per colony with a maximum value of 12 oocytes per polyp and this compares favourably with colony oocyte output from other cnidarian species, showing different strategies. Thus, Chia \& Crawford (1973) showed that the shallow water sea pen Ptilosarcus guerneyi has a fecundity of 200000 oocytes per colony and 20 to 25 oocytes per polyp (this last figure is a rough approximation based on large colonies). The Mediterranean gorgonian Eunicella singularis produces 6000 planulae per colony with an average of 4 oocytes per polyp, for a medium size female of approximately $35 \mathrm{~cm}$ (Weinberg \& Weinberg 1979), and the Antarctic gorgonian Thouarella variabilis follows a similar strategy (13500 oocytes per colony, 1 oocyte/ polyp) (rough approximation based on a colony of about $20 \mathrm{~cm}$ length and the reproductive data by Brito et al. 1997). On the other hand, the pennatulacean Umbellula lindahli has only 2000 oocytes per colony (Tyler et al. 1995) but about 200 oocytes per polyp (for a specimen of 10 polyps and $30 \mathrm{~cm}$ length). A relatively small number of oocytes per polyp can thus be compensated by the high number of polyps in the colony.

\section{Intra-colonial variation in fecundity}

Variability in fecundity within an individual colony has been studied frequently in octocorals (e.g. Brazeau \& Lasker 1990, Coma et al. 1995a). Similar functional characteristics have been postulated for all segments along a colony branch, on the basis of the branch formation pattern (Brazeau \& Lasker 1988), but recent reproductive studies have contradicted this assumption by revealing differences in reproductive effort within individual colonies (Coma et al. 1995b). Soong \& Lang (1992) postulated that a decreasing fecundity related with increasing branch order might be caused by different capture rates along the colonies, themselves related to differences in access to water flow. In the Antarctic gorgonian Thouarella variabilis (Brito et al. 1997) the distal regions of both male and female colonies contain more polyps in the first reproductive or immature stages, with the mature stages distributed relatively evenly between the middle and proximal regions of the secondary branches. Brito et al. (1997) hypothesised that the polyps in a colony could have different functions, which may explain the different distribution of reproductive polyps along the colony, and that the reproductive polyps enter a quiescent stage receiving the food through the solenia from the most distal non-reproductive polyps in the secondary branches. In Ainigmaptilon antarcticum the most fecund zones are the apical and medial. Two possible explanations could be considered: (1) prey capture is higher in the upper colony parts and is translated into a higher investment in reproduction; and (2) polyp 
Table 3. Ainigmaptilon antarcticum. Three-way ANOVA comparing gonad size $(\mu \mathrm{m})$. (Box-Cox transformed) between (a) cruises, (b) colony zone, and (c) sexes

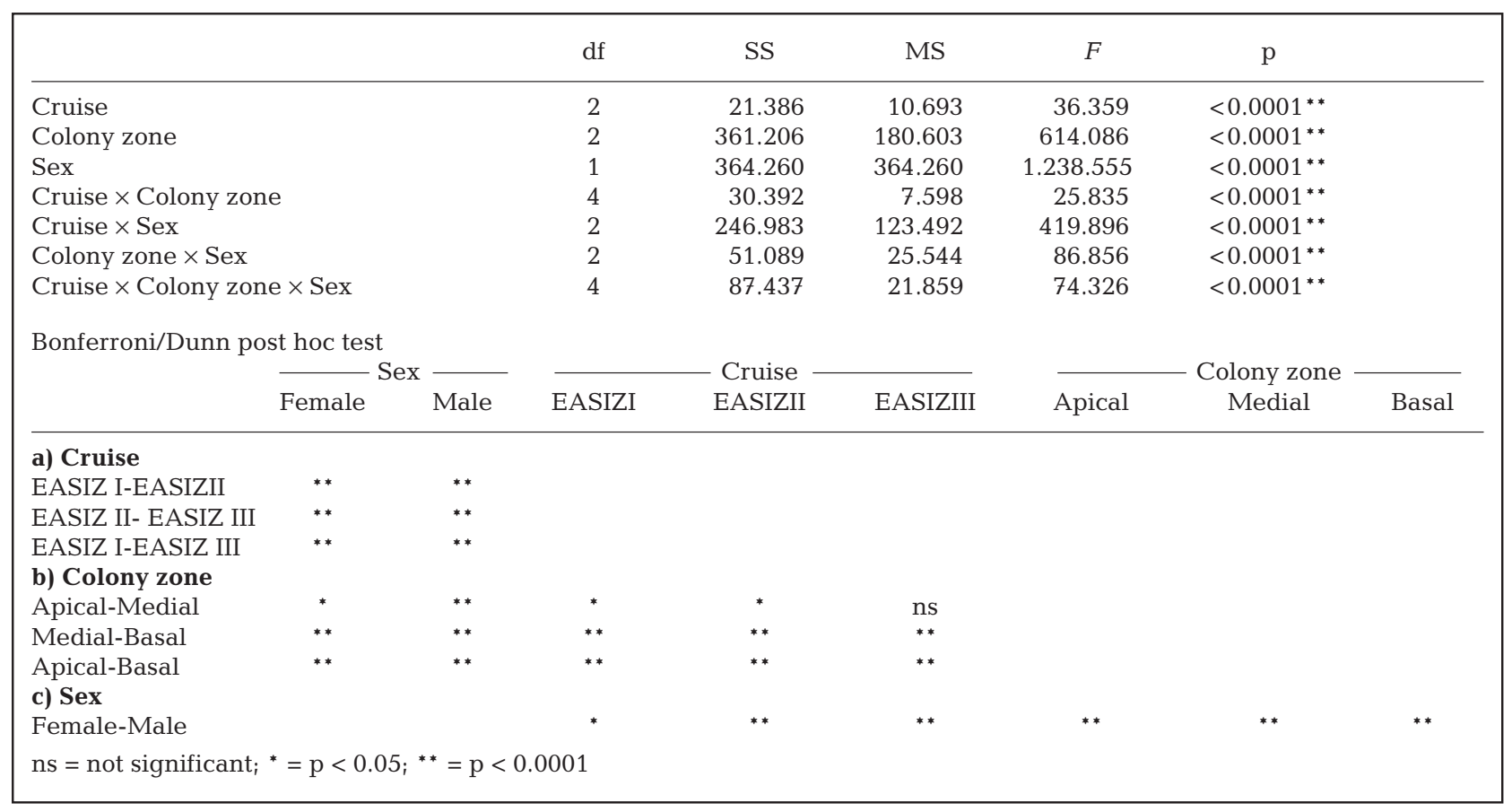

function might be differentiated throughout the colony (Hughes 1989), which would mean that the basal polyps invest more energy into creating colony structure than in reproduction. At present we do not have the data to verify these 2 hypotheses.

\section{Gametogenesis}

Studies on the duration and seasonality of gametogenesis in octocorals have been undertaken in several geographical areas. Different gametogenesis modes have been observed, related in some cases to biological processes. For example, Dahan \& Benayahu (1997) suggested that the 2 annual relatively persistent phytoplankton blooms at Eilat (Red Sea) supply the metabolic demands for gametogenesis in the soft coral Dendronephthya hemprichi, allowing the year-round gamete release. In contrast, most deep-sea anemones have a seasonal reproductive cycle (e.g. Van Praet 1990, Van Praet et al. 1990), although Rice et al. (1992) could find no evidence of seasonal reproduction in the pennatulacean Kophobelemnon stelliferum at 365 to $1600 \mathrm{~m}$ depth in the Porcupine Seabight. A reproductive cycle of more than 1 yr has been observed in some octocoral species. This is the case in the tropical gorgonian Plexaura A (Brazeau \& Lasker 1989), the alcyonaceans, Lobophytum crassum (Yamazo et al. 1981) and Sarcophytum glaucum (Benayahu \& Loya 1986), and in the Mediterranean gorgonian Corallium rubrum (Vighi 1970). Ainigmaptilon antarcticum shows 2 modes in the frequency distribution of the oocytes in summer, which might correspond to 2 generations of oocytes. This suggests that the reproductive cycle in this species may last at least 18 mo and possibly as long as $2 \mathrm{yr}$, as has been observed in several deep-sea anemones, alcyonaceans and gorgonians (e.g. Benayahu \& Loya 1986, Van Praet 1990, Van Praet et al. 1990).

In contrast to the oocytes, the size frequency distributions of spermatic cysts in Ainigmaptilon antarcticum did not show a clear division into 2 size classes. This could indicate a development cycle of less than $1 \mathrm{yr}$, as has been demonstrated for some soft corals (see Benayahu et al. 1990, Dahan \& Benayahu 1997), stony corals (see Harrison \& Wallace 1990) and gorgonians, in which spermaries develop quickly to maturity within weeks prior to spawning (Brazeau \& Lasker 1989, Coma et al. 1995a).

Similarities have been found in the gametogenesis features of Ainigmaptilon antarcticum and the deepsea anthozoan species (e.g. Riemann-Zürneck 1976 for the actiniarian Actinostola spetsbergensis). These similarities between Antarctic and deep-sea species have also been observed among other benthic invertebrates (Arntz et al. 1994, Arntz \& Gili 2001). Brey et al. (1996) suggested that the reproductive strategies of species living on the Antarctic shelf could be similar to those 


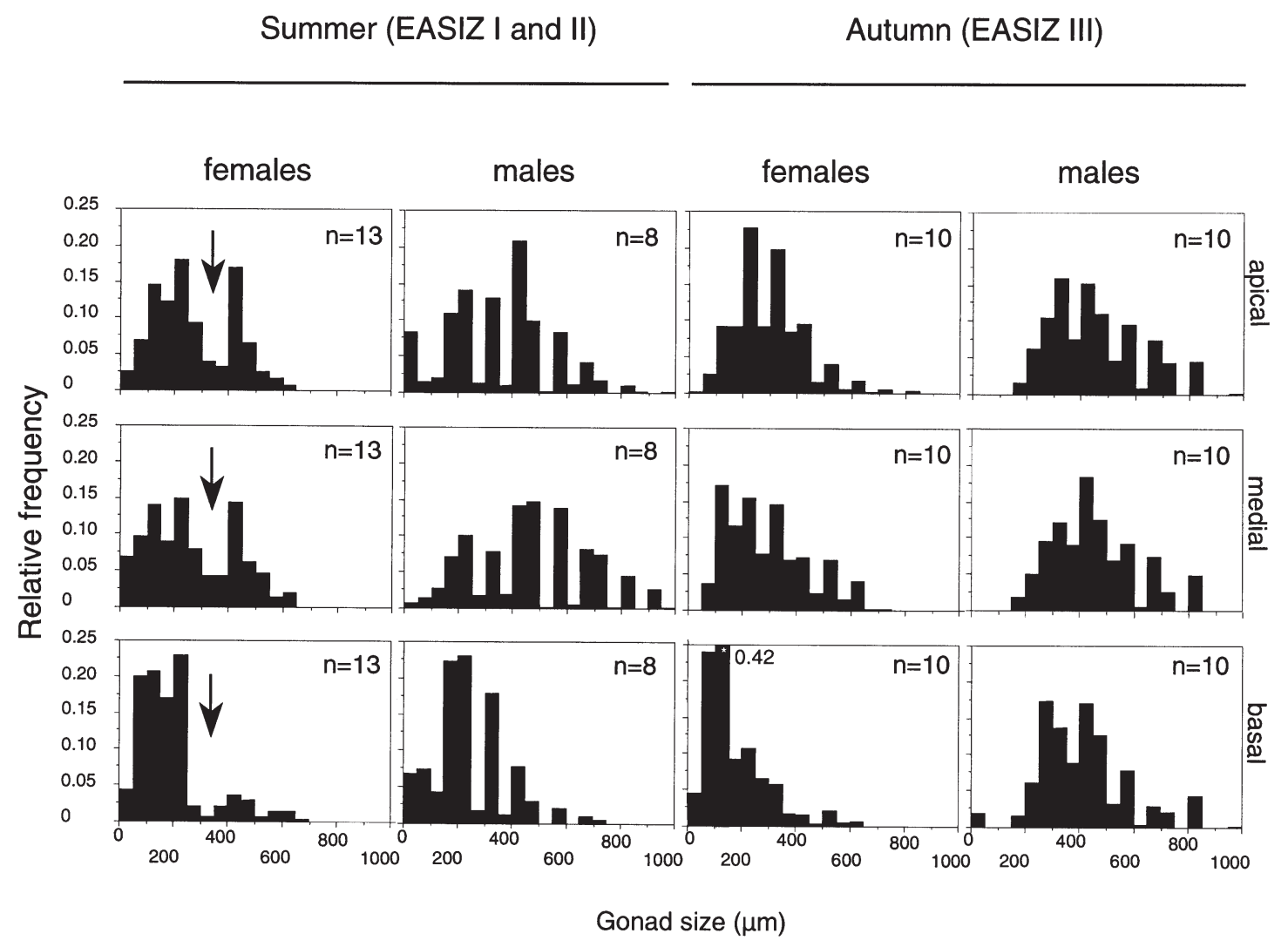

Fig. 6. Ainigmaptilon antarcticum. Size frequency distribution of oocyte and spermatic cysts along the 3 zones of the colony (apical, medial and basal) in summer and autumn

species living in the deep sea because of the migration of continental shelf species into deeper water at times of maximal glacial extension.

\section{Oocyte size as an indicator of reproductive mode: direct development or short-lived larva?}

Number and size of oocytes are related to reproductive modes in octocorals (Coma et al. 1995a). Species with non-feeding, non-pelagic, lecithotrophic larvae produce a few large eggs that are brooded until the larva is mature (Chia \& Crawford 1973).

In Ainigmaptilon antarcticum the maximum oocyte size is $900 \mu \mathrm{m}$ in diameter. This is unusually large, suggesting a brooding strategy (Chia \& Crawford 1973). In general, large oocyte sizes (usually >600 $\mu \mathrm{m}$ ) are found in species with internal fertilisation and brooding incubation mode (e.g. Muricea fruticosa, Grigg 1977; Anthelia glauca, Benayahu \& Schleyer 1998; Thouarella variabilis, Brito et al. 1997). However, we did not find any direct evidence whether $A$. antarcticum is either a brooding or a broadcasting species. The decrease in the frequency of large oocytes is clear between summer and autumn samples, and indicates that spawning of (presumably non-fertilized) oocytes occurs during late summer and autumn. This would be consistent with observations from other octocoral species at lower latitudes (Table 4); e.g. Benayahu et al. 1989 for Heteroxenia fuscescens and Grigg 1977 for Muricea californica. However, differences among geographical regions could also be the result of differences in time invested in egg production as a consequence of local trophic constraints. This might be the case in polar regions, which are characterised by a markedly seasonal primary production. Looking at Fig. 7 it can be seen that in all investigated Antarctic and deep-sea species, the oocytes are big $(>600 \mu \mathrm{m})$, whereas in other regions the range is much wider. However, it is also important to take into account that the information about Antarctic and deep-sea species is still limited, and conclusions may change as more data become available.

Observations of Antarctic octocorals and other invertebrate species during the EASIZ III cruise (autumnearly winter) showed an increased incidence of embryo or larval release, and of number of embryos and larvae ready to be released, compared to the summer. The presence of planulae in the water column all year round has been recently demonstrated by Stanwell- 
Table 4. Ainigmaptilon antarcticum. Maximum oocyte size, fertilization type and incubation mode, and geographic area for different gorgonian species (data are arranged by oocyte sizes)

\begin{tabular}{|lccccl}
\hline Species & $\begin{array}{c}\text { Max. oocyte } \\
\text { size }(\mu \mathrm{m})\end{array}$ & Fertilization & $\begin{array}{c}\text { Incubation } \\
\text { mode }\end{array}$ & $\begin{array}{c}\text { Geographic } \\
\text { area }\end{array}$ & Reference \\
\hline Corallium rubrum & 330 & Internal & Brooder & Mediterranean & Vighi (1970) \\
Paramuricea clavata & 500 & - & Surface & Mediterranean & Coma et al. (1995a) \\
Muricea fructicosa & 600 & Internal & Brooder & NE Pacific & $\begin{array}{l}\text { Grigg (1977) } \\
\text { Ptilosarcus guerney }\end{array}$ \\
Plexaura A & 600 & External & - & NE Pacific & Chia \& Crawford (1973) \\
Anthelia glauca & 633 & External & - & E Pacific & Brazeau \& Lasker (1989) \\
Plexaura homomalla & 640 & Internal & Brooder & SW Indic & Benayahu \& Schleyer (1988) \\
Sarcophytum glaucum & 650 & External & - & Caribbean & Martin (1982) \\
Thouarella variabilis & 660 & Internal & Brooder & Antarctic Peninsula & Benayahu \& Loya (1986) \\
Muricea californica & 700 & Internal & Brooder & NE Pacific & Grigg (1997) \\
Fannyella rossii & 700 & Internal & Brooder & E Weddell Sea & Orejas et al. (unpubl. data) \\
Pennatula aculeata & 880 & External & - & NW Atlanctic & Eckelbarger et al. (1998) \\
Ainigmaptilon antarcticum & 900 & Internal & - & E Weddell Sea & This study \\
Heteroxenia fuscescens & 900 & Internal/External & Brooder & Red Sea & Benayahu et al. (1989) \\
Briaremum asbestinum & 900 & Internal & Surface & Caribbean & Brazeau \& Lasker (1989) \\
Heliophora coerulea & 920 & Internal & Surface & SW Pacific & Babcock (1990) \\
Eunicella singularis & - & Internal & Brooder & Mediterranean & Weinberg \& Weinberg (1979) \\
\hline
\end{tabular}

Smith et al. (1999) at Signy Island, Antarctica. Planktonic embryos in autumn have also been observed in bivalves (see Bosch \& Pearse 1988), as well as ripe gonads in echinoderms (Pearse \& Giese 1966). These observations strengthen the idea that many Antarctic invertebrates release lecithotrophic larvae during autumn to have juveniles ready to settle during the best feeding period (spring and summer).

According to Brito et al. (1997) spawning of the Antarctic gorgonian Thouarella variabilis occurs presumably throughout the Antarctic summer and the swimming planulae settle soon after release. These results are in line with the evidence that the development of the first feeding polyp after larval settlement in gorgonians, and probably also in other sessile invertebrates such as the rhagon stage in sponges, takes longer than previously reported, especially in polar regions (e.g. Simpson 1984). Thus, only the functional polyp will profit from the plankton blooms during the favourable season, together with the planktotrophic larvae produced by other benthic organisms. An extended period of polyp development could be a life cycle strategy to avoid the unfavourable trophic season in polar regions.

To summarise, Ainigmaptilon antarcticum is characterised by an extended oogenesis period ( $>1 \mathrm{yr}$ ), which agrees with the reduction in development rates with decreasing temperature as has been demonstrated for a wide range of invertebrate species (reviewed in Pechenik 1987). In A. antarcticum spawning seems to be delayed until the autumn-winter season, as we also observed in some Thouarella spp. during the EASIZ III cruise. The decrease in the relative frequency of large oocytes in autumn has been used as an indicator of the spawning season (following Van Praet 1990, Brondson 1993). The absence of larval stages of $A$. antarcticum during the EASIZ III cruise was surprising, considering that many octocoral species had larvae ready to be released, leaving the reproduction of $A$. antarcticum still as a mystery. The type of fertilization (external or internal) could not be determined. However, the absence of embryonic or larval stages in the polyp channels and the decrease of large oocyte frequency suggest that the process of fertilization probably occurs in the water layers close to the sea floor during autumn or winter.

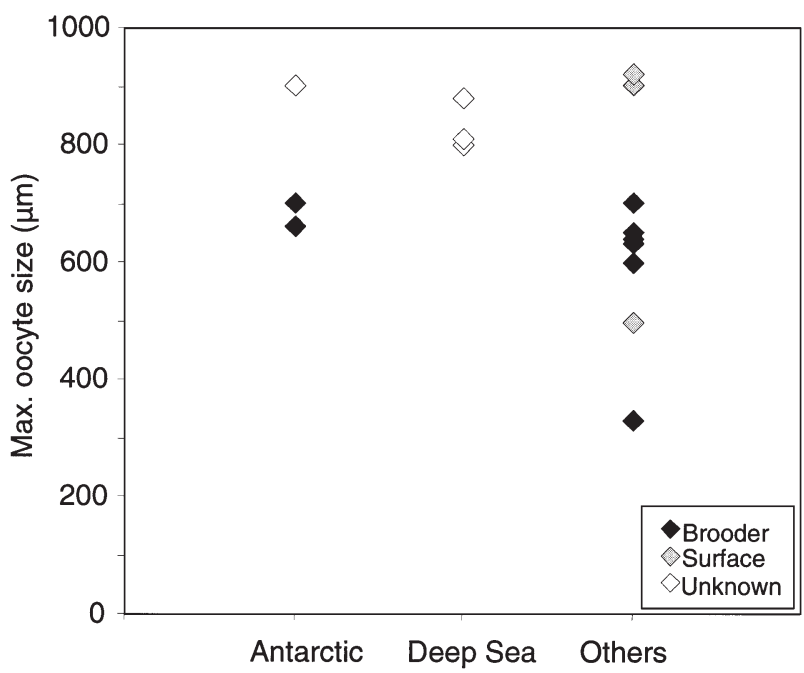

Fig. 7. Ainigmaptilon antarcticum. Maximum oocyte size by mode of incubation in different latitudes (sources are as in Table 4) 
In conclusion, our present data do not allow us to state any special Antarctic features in the reproductive biology of Ainigmaptilon antarcticum, although there are indications that it could be the case.

Acknowledgements. Financial support for this study was provided by a DAAD fellowship (A/96/13073), by a European Commission fellowship within the programme 'Training and Mobility of Researchers' (TMR-CT97-2813), and by CICYT (Spanish Antarctic Research Programme) grants ANT971533-E, ANT98-1739-E, and ANT099-1608-E. We are indebted to Drs. Miriam Fernández, Thomas Brey and Andrew Clarke whose comments very much improved the manuscript. We also thank Isabel Alfonso, Christianne Hasemann and Patricia Pinto for their laboratory assistance. The SEM observations were assisted by Kerstin Beyer and Ute Bock. The authors are grateful to many colleagues who helped on board, and especially to officers and crew of RV 'Polarstern' for their co-operation and hospitality during the 3 EASIZ cruises.

\section{LITERATURE CITED}

Arntz W, Brey T (2001) The expedition Antarktis XVII/3 (EASIZ III) of RV 'Polarstern' to the eastern Weddell Sea in 2000. Ber Polarforsch 402:181

Arntz WE, Gili JM (2001) A case for tolerance in marine ecology: Let us not put the baby with the bathwater. In: Gili JM, Pretus JL, Packard TT (eds) A marine science odyssey into the 21st century. Sci Mar 65 (2):283-299

Arntz W, Gutt J (1997) The expedition Antarktis XIII/3 (EASIZ I) of RV 'Polarstern' to the eastern Weddell Sea in 1996. Ber Polarforsch 249:148

Arntz W, Gutt J (1999) The expedition Antarktis XV/3 (EASIZ II) of RV 'Polarstern' to the eastern Weddell Sea in 1998. Ber Polarforsch 301:229

Arntz WE, Brey T, Gerdes D, Gorny M, Gutt J, Hain S, Klages M (1992) Patterns of life history and population dynamics of benthic invertebrates under the high Antarctic conditions of the Weddell Sea. In: Colombo G, Ferrari I, Ceccherelli VU, Rossi R (eds) Marine eutrophication and population dynamics. 25th Eur Mar Biol Symp, Ferrara, Italy, September 1990. Olsen \& Olsen, Fredensborg 370: 221-230

Arntz WE, Brey T, Gallardo VA (1994) Antarctic zoobenthos. Oceanogr Mar Biol Annu Rev 32:241-304

Babcock R (1990) Reproduction and development of the blue coral Heliopora coerulea (Alcyonaria: Coenothecalia) Mar Biol 104: 475-481

Barnes DK, Clarke A (1998) Seasonality of polypide recycling and sexual reproduction in some erect Antarctic bryozoans. Mar Biol 131:647-658

Barthel D, Gutt J (1992) Sponge associations in the eastern Weddell Sea. Ant Sci 4:137-150

Bayer FM (1954) A new species of the gorgonacean genus Ainigmaptilon Dean (Coelenterata: octocorallia). J Wash Acad Sci 40 (9):295-298

Behety-González PA, Guardiola M (1979) Ciclo reproductivo de Plexaura homomalla (Esper, 1792) forma kuekenthali Moser, 1921 (Gorgonacea). Acad Cienc Cuba Ser Biol 3: 99-104 (in Spanish)

Benayahu Y, Loya Y (1984) Life history studies on the Red Sea soft coral Xenia macrospiculata Gohar, 1940. I.
Annual dynamics of gonadal development. Biol Bull 166:32-43

Benayahu Y, Loya Y (1986) Sexual reproduction of a soft coral: synchronous and brief annual spawning of Sarcophyton glaucum (Quoy and Gaimard, 1833). Biol Bull 170: 32-42

Benayahu Y, Schleyer MH (1988) Reproduction in Anthelia glauca (Octocorallia: Xeniidae). II. Transmission of algal symbionts during planular brooding. Mar Biol 131: 433-442

Benayahu Y, Berner T, Achituv Y (1989) Development of planulae within a mesogleal coat in the soft coral Heteroxenia fuscescens. Mar Biol 100:203-210

Benayahu Y, Weil D, Kleinman M (1990) Radiation of broadcasting and brooding patterns in coral reef alcyonaceans. In: Hoshi M, Yamashita O (eds) Advances in invertebrate reproduction. Vol. 5. Elsevier Science Publishers, New York, 323-328

Bosch I, Pearse JP (1988) Seasonal pelagic development and juvenile recruitment of the bivalve Laternula elliptica in McMurdo Sound, Antarctica. Am Zool 28:89A

Brazeau DA, Lasker HR (1988) Inter- and intraspecific variation in gorgonian colony morphology: quantifying branching patterns in arborescent animals. Coral Reefs 7:139-143

Brazeau DA, Lasker HR (1989) The reproductive cycle and spawning in a Caribbean gorgonian. Biol Bull 176:1-7

Brazeau DA, Lasker HR (1990) Sexual reproduction and external brooding by the Caribbean gorgonian Briareum asbestinum. Mar Biol 104:465-474

Brey T, Dahm C, Gorny M, Klages M, Stiller M, Arntz WE (1996) Do Antarctic benthic invertebrates show an extended level of eurybathy? Ant Sci 8(1):3-6

Brito TAS, Tyler PA, Clarke A (1997) Reproductive biology of the Antarctic octocoral Thouarella variabilis Wright and Studer 1889. Proc 6th Int Conf Coelenterate Biology, Natural History Museum of Leiden, The Netherlands, p 63-69

Bronsdon SK, Tyler PA, Rice AL, Gage JD (1993) Reproductive biology of two epizoic anemones from the deep NorthEastern Atlantic Ocean. J Mar Biol Assoc UK 73: 531-542

Carlgren O (1943) Die Alcyonarien-Gattungen Ainigmaptilon und Lycurus. K Fysiogr Sallsk Lund Forh 13(10):1-7

Chia FS, Crawford BJ (1973) Some observations on gametogenesis, larval development and substratum selection of the sea-pen Ptilosarcus guerneyi. Mar Biol 23:73-82

Coma R, Lasker HR (1997) Effects of spatial distribution and reproductive biology on in situ fertilization rates of a broadcast-spawning invertebrate. Biol Bull 193:20-29

Coma R, Ribes M, Zabala M, Gili JM (1995a) Reproduction and cycle of gonadal development in the Mediterranean gorgonian Paramuricea clavata. Mar Ecol Prog Ser 117: 173-183

Coma R, Zabala M, Gili JM (1995b) Sexual reproductive effort in the Mediterranean gorgonian Paramuricea clavata. Mar Ecol Prog Ser 117:185-192

Dahan M, Benayahu Y (1997) Reproduction of Dendron ephthya hemprichi (Cnidaria: octocorallia): year-round spawning in an azooxanthellae soft coral. Mar Biol 129: 573-579

Dayton PK (1990) Polar benthos. In: Smith WO (ed) Polar oceanography. Part B: Chemistry, biology and geology. Academic Press, San Diego, p 631-685

Dayton PK, Robilliard RT, Paine LB, Dayton LB (1974) Biological accommodation in the benthic community at McMurdo Sound, Antarctica. Ecol Monogr 44(1):105-128

Dean I (1926) Ainigmaptilon haswelli, n. g. et sp.: a new Alcyonarian type. J Linn Soc Zool 36(244):337-344

Eckelbarger KJ, Tyler PA, Langton RW (1998) Gonadal mor- 
phology and gametogenesis in the sea pen Pennatula aculeata (Anthozoa: Pennatulacea) from the Gulf of Maine. Mar Biol 98(132):677-690

Gabe M (1968) Technique histologique. Massou et Cie Editeurs, Paris (in French)

Gili JM, Ros JD (1985) Estudio cuantitativo de tres poblaciones circalitorales de cnidarios bentónicos. Invest Pesq 49:323-352 (in Spanish)

Gili JM, Murillo J, Ros J (1989) The distribution patterns of benthic cnidarians in the Western Mediterranean. Sci Mar 53:19-35

Gili JM, Arntz WE, Filipe P, López P, Orejas C, Ros JD, Teixidó $N$ (1999) The role of benthic suspension feeders in Antarctic communities. In: Arntz WE, Gutt J (eds) The expedition Antarktis XV/3 (EASIZ II) of 'Polarstern' to the eastern Weddell Sea in 1998. Ber Polarforsch 301:30-83

Goldberg W, Hamilton R (1974) The sexual cycle in Plexaura homomalla. In: Bayer FM, Weinheimer AJ (eds) Prostaglandins from Plexaura homomalla: ecology, utilization, and conservation of a major medical marine resource. University of Florida Press, Coral Gables, p 58-61

Grigg RW (1977) Population dynamics of two gorgonian corals. Ecology 58:278-290

Harrison PL, Wallace CC (1990) Reproduction, dispersal and recruitment of scleractinian corals. In: Dubinsky Z (ed) Ecosystems of the world. Elsevier Science Publishers, Amsterdam, p 133-204

Hecker B (1994) Unusual megafaunal assemblages on the continental slope off Cape Hatteras. Deep-Sea Res Part II 41(4-6):809-834

Hughes RG (1989) A functional biology of clonal organisms. Chapman and Hall, London

Hughes RN, Cancino JM (1985) An ecological overview of cloning in Metazoa. In: Jackson JBC, Buss LW, Cook RE (eds) Population biology and evolution of clonal organisms. Yale University Press, New Haven, CT, p 153-186

Hughes TP, Jackson JBC (1980) Do corals lie about their age? Some demographic consequences of partial predation, fission and fusion. Science 209:713-715

Johansen DA (1940) Plant microtechniques. McGraw-Hill, New York

Jones CG, Lawton JH, Shachak M (1997) Positive and negative effects of organisms as physical ecosystem engineers. Ecology 78:1946-1957

Kinzie RA (1970) The ecology of the gorgonians (Cnidaria, Octocorallia) of Discovery Bay, Jamaica. PhD thesis, Yale University, New Haven, CT

Kinzie RA (1973) The zonation of West Indian gorgonians. Bull Mar Sci 23:93-155

Kinzie RA (1974) Plexaura homomalla: the biology and ecology of a harvestable marine resource. In: Bayer FM, Weinheimer AJ (eds) Prostaglandinas from Plexaura homoma1la. Studies in tropical oceanography, Vol. 12. Rosenstiel School of Marine and Atmospheric Sciences, University of Miami Press, Coral Gables, FL, p 22-38

Langton RW, Robinson WE, Schick D (1987) Fecundity and reproductive effort of sea scallops Placopecten magellanicus from the Gulf of Maine. Mar Ecol Prog Ser 37:19-25

Langton RW, Langton EW, Théroux RB, Uzmann JR (1990) Distribution, behaviour and abundance of sea-pens, Pennatula aculeata, in the Gulf of Maine. Mar Biol 107: 463-469

Lasker HR, Gottfried MD, Goffroth MA (1983) Effects of depth on the feeding capability of two octocorals. Mar Biol 73:73-78

Levinton JS (1982) Marine ecology. Prentice-Hall, Englewood Cliffs, NJ

Lincoln RJ, Boxshall GA, Clark PF (1998) A dictionary of eco- logy, evolution and systematics, 2nd edn. Cambridge University Press, Cambridge

Martin E (1982) Ciclo reproductivo, proporción sexual y fecundidad del coral blando Plexaura homomalla (Esper.) en el Mar Caribe Mexicano. (Octocorallia: Plexauridae). An Inst Cienc Mar Limnol Univ Nac Auton Mex 9:359-380 (in Spanish)

Miller KJ (1998) Short-distance dispersal of black coral larvae: inference from spatial analysis of colony genotypes. Mar Ecol Prog Ser 163:225-233

Molander AR (1929) Die Octactiniarien. Further zoological results of the Swedish Antarctic expedition 1901-1903, Vol II, No. 2. PA Norstedt \& Soner, Stockholm

Morisita M (1962) $I_{\mathrm{d}}$-index, a measure of dispersion of individuals. Res Popul Ecol 4:1-7

Muirhead A, Tyler PA, Thurston MH (1986) Reproductive biology and growth of the genus Epizoanthus (Zoanthidea) from the North-East Atlantic. J Mar Biol Assoc UK 66:131-143

Muzik K (1982) Octocorallia (Cnidaria) from Carrie Bow Cay, Belize. In: Rutzler K, MacIntyre JG (eds) The Atlantic Barrier Reef System at Carrie Bow Cay, Belice I. Structure and communities. Smithson Contrib Mar Sci 12:309-316

Pearse JS, Giese AC (1966) Food, reproduction and organic constitution of the common Antarctic echinoid Sterechinus neumayeri (Meissner). Biol Bull 130:387-401

Pechenik JA (1987) Environmental influences of larval survival and development. Reprod Mar Invertebr 9:551-608

Pennington JT (1985) The ecology of fertilisation of echinoid eggs: the consequences of sperm dilution, adult aggregation, and synchronous spawning. Biol Bull 169:417-430

Picken GB (1980) The distribution, growth, and reproduction of the Antarctic limpet Nacella (Patinigera) concinna (Strebel, 1980). J Exp Mar Biol Ecol 42:71-85

Poulin E, Féral JP (1996) Why are there so many species of brooding Antarctic echinoids? Evolution 50(2):820-830

Rice AL, Tyler PA, Paterson GJL (1992) The pennatulacean Kophobelemnon stelliferum (Cnidaria: Octocorallia) in the Porcupine Seabight (North-east Atlantic Ocean). J Mar Biol Assoc UK 72:417-434

Riemann-Zürneck K (1976) Reproductive biology, oogenesis and early development in the brood-caring sea anemone Actinostola spetsbergensis (Anthozoa: Actiniaria). Helgol Wiss Meeresunters 28:239-249

Sebens KP (1982) The limits to indeterminate growth: an optimal size model applied to passive suspension feeders. Ecology 63:209-222

Simpson TL (1984) The cell biology of sponges. SpringerVerlag, New York

Sokal RR, Rohlf FJ (1995) Biometry, 2nd end. WH Freeman, San Francisco

Soong K, Lang JC (1992) Reproductive integration in reef corals. Biol Bull 183:418-431

Stanwell-Smith D, Peck LlS, Clarke A, Murray AWA, Todd CD (1999) The distribution, abundance and seasonality of pelagic marine invertebrate larvae in the maritime Antarctic. Phil Trans R Soc Lond B Biol Sci 354:471-484

Starmans A, Gutt J, Arntz W (1999) Mega-epibenthic communities in Arctic and Antarctic shelf areas. Mar Biol 135: 269-280

Tyler PA, Brondson SK, Young CM, Rice AL (1995) Ecology and gametogenic biology of the genus Umbellula (Pennatulacea) in the North Atlanctic Ocean. Int Rev Gesamten Hydrobiol 80:187-199

Van Praet M (1990) Gametogenesis and the reproductive cycle in the deep-sea anemone Paracalliactis stephensoni (Cnidaria: Actiniaria). J Mar Biol Assoc UK 70:163-172 
Van Praet M, Rice AL, Thurston MH (1990) Reproduction in two deep-sea anemones (Actiniaria); Phelliactis hertwigi and $P$. robusta. Prog Oceanogr 24:207-222

Versluys J (1906) Die Gorgoniden der Siboga-Expedition II. Die Primnoidae. Siboga-Exped Monogr 13(A):1-187

Vighi M (1970) Ricerche sul ciclo reproductivo del corallo rosso (Corallium rubrum (L.)) del Promontorio di Porfino. Atti Accad Lincei Roma 10 (Ser. 8):1-26 (in Italian)

Voß J (1988) Zoogeographie und Gemeinschaftsanalyse des Makrozoobenthos des Weddellmeeres (Antarktis). Ber Polarforsch 45:1-145 (in German)

Wahle CM (1983) The roles of sex, size and injury in sexual reproduction among Jamaican gorgonians. Am Zool 24: 961

Weinberg S (1979) The light dependent behaviour of planula larvae of Eunicella singularis and Corallium rubrum and its implications for octocorallian ecology. Bijdr Dierkd 49: $16-30$

Weinberg S (1980) Autoecology of shallow-water Octocorallia from Mediterranean rocky sustrata. II. Marseille, Côte d'Azur and Corsica. Bijdr Dierkd 50:73-86

Editorial responsibility: Otto Kinne (Editor), Oldendorf/Luhe, Germany
Weinberg S, Weinberg F (1979) The life cycle of a gorgonian: Eunicella singularis (Esper 1794). Bijdr Dierkd 48:127-140

White MG (1984) Marine benthos. In: Laws RM (ed) Antarctic ecology, Vol 2. Academic Press, London p 421-461

Williams GB (1976) Aggregation during settlement as a factor in the establishment of coelenterate colonies. Ophelia 15: $57-64$

Wright EP, Studer T (1889) Report on the Alcyonaria collected by HMS Challenger during the years 1873-1876. Rept Sci Res Challenger Zool 31:1-314

Yamazo KM, Sato M, Yamashiro H (1981) Reproductive biology of an alcyonacean coral Lobophytum crassum Marenzeller. Proc 4th Int Coral Reef Symp 2:671-678

Yoshioka PM, Yoshioka BB (1989) A multispecies, multiscale analysis of spatial pattern and its application to a shallowwater gorgonian community. Mar Ecol Prog Ser 54: $247-264$

Young CM, Tyler PA, Cameron JL, Rumrill SG (1992) Seasonal breeding aggregations in low-density populations of the bathyal echinoid Stylocidaris lineata. Mar Biol 113: 603-612

Submitted: December 18, 2000; Accepted: September 4, 2001 Proofs received from author(s): March 18, 2002 